\title{
An external sensing system in Plasmodium falciparum-infected erythrocytes
}

Yang Wu', Laura N. Cruz², Tadge Szestak1, Gavin Laing1', Gemma R. Molyneux', Celia R. S. Garcia² and Alister G. Craig ${ }^{1 *}$

\begin{abstract}
Background: A number of experiments have previously indicated that Plasmodium falciparum-infected erythrocytes (pRBC) were able to sense host environment. The basis of this ability to detect external cues is not known but in screening signalling molecules from pRBC using commercial antibodies, a $34 \mathrm{kDa}$ phosphorylated molecule that possesses such ability was identified.
\end{abstract}

Methods: The pRBC were exposed to different culture conditions and proteins were extracted for 1D or 2D gel electrophoresis followed by Western blot. The localization of $34 \mathrm{kDa}$ protein was examined by biochemical fractionation followed by Western blot. High-resolution mass spectrometric analysis of immune precipitants was used to identify this protein and real-time quantitative reverse transcriptase polymerase chain reaction was used for detecting mRNA expression level.

Results: The $34 \mathrm{kDa}$ protein was called PfAB4 has immediate responses (dephosphorylation and rapid turnover) to host environmental stimuli such as serum depletion, osmolality change and cytokine addition. PfAB4 is expressed constitutively throughout the erythrocytic lifecycle with dominant expression in trophozoites $30 \mathrm{~h}$ post-infection. Tumour necrosis factor (TNF) treatment induced a transient detectable dephosphorylation of PfAB4 in the ItG strain ( 2 min after addition) and the level of expression and phosphorylation returned to normal within 1-2 h. PfAB4 localized dominantly in pRBC cytoplasm, with a transient shift to the nucleus under TNF stimulation as shown by biochemical fractionation. High-resolution mass spectrometric analysis of immune precipitants of AB4 antibodies revealed a 34 kDa PfAB4 component as a mixture of proliferating cellular nuclear antigen-1 (PCNA1) and exported protein-2 (EXP2), along with a small number of other inconsistently identified peptides. Different parasite strains have different PfAB4 expression levels, but no significant association between mRNA and PfAB4 levels was seen, indicating that the differences may be at the post-transcriptional, presumably phosphorylation, level. A triple serine phosphorylated PCNA1 peptide was identified from the PfAB4 high expression strain only, providing further evidence that the identity of PfAB4 is PCNA1 in P. falciparum.

Conclusion: A protein element in the human malaria parasite that responds to external cues, including the proinflammatory cytokine TNF have been discovered. Treatment results in a transient change in phosphorylation status of the response element, which also migrates from the parasite cytoplasm to the nucleus. The response element has been identified as PfPCNA1. This sensing response could be regulated by a parasite checkpoint system and be analogous to bacterial two-component signal transduction systems.

\section{Background}

Protozoan parasites are capable of withstanding relatively large alterations in their external environments.

\footnotetext{
${ }^{*}$ Correspondence: alister.craig@lstmed.ac.uk

1 Department of Parasitology, Liverpool School of Tropical Medicine,

Liverpool, UK

Full list of author information is available at the end of the article
}

Signalling is perhaps a primal requirement to respond to stimuli, the signal transduction systems being able to convert an extracellular stimulus into a chemical signal that the cell can sense/perceive and recognize, and can quickly give responses to the changing environment. The malaria parasite has invested in the machinery to transduce signals [1] and a number of experiments, such 
as those carried out by Cohen et al., have indicated that Plasmodium falciparum-infected erythrocytes (pRBC) may be able to sense host environment, where passive transfer of polyclonal sera or purified immune globulin from immune adults into $P$. falciparum-infected individuals resulted in a significant reduction in blood-stage parasitaemia and recovery from clinical symptoms, but also boosted gametocyte production [2]. Plasmodium falciparum is considered a micro-aerophilic organism growing in an environment of limited oxygen content $0.5-5.0 \%$. The malaria parasite is under constant oxidative stress caused by exogenous reactive oxidant species and reactive nitrogen species (RNS) produced by the host immune system and generated by the parasite's metabolism. Accordingly, parasites have already adapted to cope with the external oxidative stress by adapting to the host environment through superoxide dismutases and thioredoxin-dependent peroxidases, as part of an antioxidant defence system of the pRBC [3]. Additionally, reversible phosphorylation has been shown to play an important role in parasite invasion [4] and intra-erythrocytic growth and development [5], through serine/threonine kinases [6-9].

$\mathrm{pRBC}$ are known to be able to activate several signalling pathways in the host: for example, MAPK and PI3 kinases/AKT pathways have been shown to be associated with malaria infection and pathogenesis via cytoadherence [10-12]. It was found that one of NF-kB family members REL-1A (P65), almost completely translocated into the nucleus within $10 \mathrm{~min}$ of pRBC-EC interaction, suggesting a direct role for parasite factors in NF-kB activation [13]. Src-family signalling mediated ectophosphorylation of CD36 on endothelium has also been demonstrated, whereby treating HDMEC with a Src-family kinase-selective inhibitor PP1 resulted in a significant reduction of $\mathrm{pRBC}$ adhesion in a flow-chamber adhesion assay [14]. However, all of these belong to the host responses to parasite infection, whereas there are only limited numbers of studies about signalling events in parasites themselves, despite the existence of an extensive kinase gene family. For example, signal transduction inside Plasmodium has been shown to be a major mechanism to control parasite development [15] with regulation in $P$. falciparum by calcium-dependent protein kinase 7 (PfCDPK7) being reported [16]. PfCDPK1 has been identified as a $\mathrm{Ca}^{2+}$-dependent effector that plays a role in microneme secretion during erythrocyte invasion [17]. Mutai and Waitumbi also suggested the existence of $P$. falciparum quorum sensing (the ability to detect conditions of overcrowding), which is more frequently seen in small-molecule signalling pathways in bacteria [18], to keep the parasite population under check [19]. However, the signalling pathways controlling parasite growth and defence have not been well studied. Therefore, research on signalling molecules from the parasite were undertaken to understand their pathways and function in parasite growth, response and defence against the host immune system.

Using a panel of commercial antibodies to several signalling transduction pathways of different species, only one molecule from $P$. falciparum parasites with the appropriate molecular weight was identified. The antibody was against human phospho-I-kappaB- $\alpha$ (IкB), an important component in the NF kappa B (NFkB) pathway of mammals. The NFKB pathway is found in almost all animal cell types, although not in $P$. falciparum, and is involved in cellular responses to stimuli such as cytokines, free radicals, ultraviolet irradiation, oxidized LDL, and bacterial or viral antigens. It mediates stress and innate immunity and plays a key role in regulating the immune response to infection $[20,21]$.

Activation of NFKB is initiated by the signal-induced degradation of IкB $\alpha$ proteins (a negative feedback regulator). ІкB $\alpha$ functions rapidly and is primarily involved in determining the temporal profiles of $\mathrm{NF} \kappa \mathrm{B}$ signalling in response to cytokines that serve intercellular communication. Rapid ІкB $\alpha$ turnover has been implicated in the high basal NFKB activity in WEHI $231 \mathrm{~B}$ immature $\operatorname{IgM}^{+} \mathrm{B}$ cells [22], primarily via activation of the IKB kinase.

PfAB4 molecule identified in this investigation has several interesting features which could resemble the responses of IкB $\alpha / \mathrm{NF \kappa} B$ in mammalian species. However, there are no NFкB and ІкB homologues per se in $P$. falciparum, therefore, the identity of the PfAB4 antibody (phosphorylated IкB $\alpha$ antibody)-reacting epitope (called PfAB4 in this study) was one of the first questions. In this paper, the discovery of a sensing system in P. falciparum and an investigation into the identity of PfAB4 are reported.

\section{Methods}

\section{Plasmodium culture}

Plasmodium falciparum isolates used in this study were mainly 3D7 [23], ItG [24] and Dd2 [25], as well as a number of patient isolates PO69, PCM-7, BC12, BC31, and GL-6 recently characterized in our laboratory [26]. Parasites were cultured in vitro in group $\mathrm{O}^{+}$human erythrocytes using previously described conditions [27, 28]. To minimize the effect of antigenic switching in culture, a batch of stabilates was prepared from a postselection culture and used for no more than three weeks. Mycoplasma contamination of the parasite culture was checked (Universal mycoplasma detecting kit, ATCC, UK). pRBC were regularly synchronized by $5 \%$ sorbitol treatment or Plasmion-gel flotation. 


\section{Sample preparation from infected erythrocytes and immunoblotting}

To study the PfAB4 expression profile in the parasites, saponin was added to the parasite culture to a final concentration of $0.05 \%$ and kept on ice for 8 min to lyse the erythrocytes. Following centrifugation at $5000 \times g$ at $4{ }^{\circ} \mathrm{C}$ for $10 \mathrm{~min}$, erythrocyte ghosts were removed and the free parasite pellets were washed twice using RPMI 1640 without serum. The pellet was dissolved in SDS sample buffer (final: $3 \%[\mathrm{w} / \mathrm{v}]$ SDS, $62 \mathrm{mM}$ Tris- $\mathrm{HCl} \mathrm{pH} 6.8$, $15 \%$ [v/v] glycerol) containing $5 \%$ ß-mercaptoethanol), vortexed and concentrated for $5 \mathrm{~min}$ at 13,000 RPM to remove any insoluble material, and this was subjected to gel electrophoresis (used as total lysate). This part of pRBC was also further extracted by the fractionation method described by Voss et al. [29] with modifications. Briefly, free parasite pellets were disrupted with ice-cold lysis buffer $(20 \mathrm{mM}$ Hepes, pH 7.8, $10 \mathrm{mM} \mathrm{KCl,} 1 \mathrm{mM}$ EDTA, $1 \mathrm{mM}$ DTT, $1 \mathrm{mM}$ PMSF, $0.65 \%$ Nonidet P-40) and incubated for $5 \mathrm{~min}$ on ice. Nuclei were pelleted at $2500 \times g$ for $5 \mathrm{~min}$, the supernatants were used as parasite cytosol. The nuclear pellet was washed twice in lysis buffer, then re-suspended in $2 \times$ pellet volume of nuclear extraction buffer (20 mM Hepes, $\mathrm{pH} 7.8,800 \mathrm{mM} \mathrm{KCl}$, $1 \mathrm{mM}$ EDTA, $1 \mathrm{mM}$ EGTA, $1 \mathrm{mM}$ DTT) and put on ice for $30 \mathrm{~min}$ with vigorous shaking every $5 \mathrm{~min}$. The extract was cleared by centrifugation at $13,000 \times g$ for $30 \mathrm{~min}$. The supernatant was used as the parasite nuclear fraction. The insoluble pellet was further washed twice with nuclear extraction buffer, pelleted and used as parasite insoluble fraction. The protein quantity was controlled by using starting material with equal amounts of culture containing the same parasitaemia and haematocrit. Cross-contamination of the nuclear fraction with other fractions was investigated using a number of markers, for example, histone-nuclear localization and localization of other molecules, e.g., HSP90 and PGK should not be in nuclear fraction. All of these fractions were diluted with $2 \times$ SDS gel sample buffer. After boiling for $5 \mathrm{~min}$, insoluble material was removed by centrifugation for $5 \mathrm{~min}$ at $13,000 \times g$ and the supernatants were run on Thermo Scientific Precise $^{\mathrm{TM}}$ precast polyacrylamide gels for protein electrophoresis using Tris-HEPES running buffer. These fractions were also precipitated by acetone-methanol method [30] and were subjected to two-dimensional (2D) electrophoresis performed as described previously [31]. Briefly, the lysate was solubilized in 2-DE rehydration buffer [ $8 \mathrm{M}$ urea, $2 \mathrm{M}$ thiourea, $2 \%$ CHAPS, $65 \mathrm{mM}$ dithiothreitol (DTT), and $0.5 \%$ ampholyte $\mathrm{pH} 4-7$ or 3-10]. The sample was vortexed and sonicated on ice ten times for $5 \mathrm{~s}$ followed by centrifugation at $15,000 \times g$ for $10 \mathrm{~min}$. The supernatant was subjected to 2-DE and the isoelectric focusing (IEF) by running on precast Amersham
$11 \mathrm{~cm} \mathrm{pH} \mathrm{3-10} \mathrm{immobiline} \mathrm{Drystrip} \mathrm{gels} \mathrm{using} \mathrm{IPG} \mathrm{phor}$ IEF Unit (Amersham). The narrow $\mathrm{pH}$ precast IPG-strips of $\mathrm{pH}$ 3.9-4.9 were from GENETIX. The running programme consists of $10 \mathrm{~h}$ for $30 \mathrm{~V}, 40 \mathrm{~min}$ for $200 \mathrm{~V}, 1 \mathrm{~h}$ for $500 \mathrm{~V}, 4 \mathrm{~h}$ for $2000 \mathrm{~V}$ and finally $8 \mathrm{~h}$ for $8000 \mathrm{~V}$. The voltage was increased gradually until a total of 80,000 vh was reached. The focused strips were equilibrated in $10 \mathrm{ml}$ equilibration solution $(50 \mathrm{mM}$ Tris $-\mathrm{HCl}, \mathrm{pH} 6.8$, $6 \mathrm{M}$ urea, $30 \%$ glycerol, $2 \%$ SDS) with reducing agent of $1 \%$ DTT for $10 \mathrm{~min}$, and $10 \mathrm{ml}$ equilibration solution with $4.5 \%$ iodoacetamide for another $10 \mathrm{~min}$. The strips were then briefly washed twice with $1 \times$ SDS gel running buffer and loaded on 10 or $12.5 \%$ SDS-PAGE gels for second dimension separation. The gels were run at constant current $40 \mathrm{~mA}$ in a Laemmli's buffer system [32] until the dye front reached the bottom of the gel. For Western blot analysis, the gel-separated proteins were transferred electrophoretically to nitrocellulose using glycine-tris-methanol buffer. The nitrocellulose membranes were blocked by 1 -hour incubation in $5 \%$ skim milk in TST buffer $(0.01 \mathrm{M}$ Tris $\mathrm{pH}$ 8.5/0.15 M sodium chloride $/ 0.1 \%$ Tween 20 ) and washed with TST buffer briefly, then probed with different primary antibodies: anti-phospho-IкB- $\alpha$ (Cell signalling); anti-EXP2 mAb 7.7 (kindly provided by Brendan S Crabb); Anti-HSP90 $\alpha$ and HSP90 $\beta$ (Cell signalling); Anti-GAPDH (Enzo); Anticalcineurin (Abgent); Anti-PGK1/2 (Santa Cruz). All primary antibodies were diluted in Calbiochem Signal Boost immunoreaction enhancer solution 1. Goat anti-rabbit or anti-mouse (as appropriate) IgG $(\mathrm{H}+\mathrm{L}$ ) horseradish peroxidase conjugate (Nordic, 1:2000) was used in enhancer solution 2 to localize antibody-antigen complexes and visualized with Pierce chemiluminescent (ECL2) systems (GE Healthcare).

\section{RNA extraction and real-time quantitative reverse transcriptase polymerase chain reaction (qRT-PCR)}

A TRIzolR Plus RNA Purification Kit (Life Technologies, UK) was used to extract total RNA from the parasite strains using late ring stages at $10 \%$ parasitaemia. RNAs were treated with DNase using a Sigma AMPD1-kit at room temperature for $15 \mathrm{~min}$, then adding stop solution and heating at $70{ }^{\circ} \mathrm{C}$ for $10 \mathrm{~min}$. Tetro cDNA synthesis kit (Bioline) was used to generate cDNA according to manufacturer's instructions with Oligo- $(\mathrm{dt})_{18}$ primer. q-PCR was carried out using Brilliant III Ultra-Fast SYBR Green QPCR Master Mix (Agilent Technologies). Standard curves were generated for each primer set by performing ten-fold serial dilutions of cDNA to produce five different concentrations of starting material. No-RT and DEPC- $\mathrm{H}_{2} \mathrm{O}$ reactions were carried out as negative controls. Details of primers are listed in Table 1. All reactions were performed in triplicate. PCR was carried out in an 
ABI Prism 7000 (Life Technologies). PCR cycling conditions were $95^{\circ} \mathrm{C}$ for $3 \mathrm{~min}$, followed by 40 cycles of $95^{\circ} \mathrm{C}$, $10 \mathrm{~s} / 60{ }^{\circ} \mathrm{C}, 10 \mathrm{~s}$ and a final cycle of $95{ }^{\circ} \mathrm{C}, 1 \mathrm{~min}, 55^{\circ} \mathrm{C}$ for $30 \mathrm{~s}, 95^{\circ} \mathrm{C}$ for $30 \mathrm{~s}$. Adenylosuccinate lyase (ASL) and seryl tRNA synthetase (STS) were used as internal control genes [33]. Relative quantitation was calculated using the comparative $\mathrm{Ct}$ method $(\Delta \Delta \mathrm{Ct}$; Applied Biosystems Reference Manual, User Bulletin). Ct values for transcripts of both the reference gene and specific genes were below 30 in all samples. Traditional RT-PCR was also carried out using generated cDNA as template with PFgene-specific primers and amplification products were ligated directly into the TA cloning vector, pCRI1 (Invitrogen) and sequenced to confirm the products.

\section{Immunoprecipitation (IP) and co-IP using AB4 antibody with Dynabeads ${ }^{\circledR}$}

This is a powerful technique to specifically pull down molecules reacting directly with antibodies (IP) and to indirectly capture proteins that are bound to a specific target protein (co-IP). 3D7-infected and uninfected erythrocytes (used as control) were disrupted by saponin lysis at $4{ }^{\circ} \mathrm{C}$ and washed with RPMI medium without serum. The parasite pellet was then disrupted with IP lysis buffer $(50 \mathrm{mM}$ Tris- $\mathrm{HCl} \mathrm{pH} 7.4 / 150 \mathrm{mM}$ $\mathrm{NaCl} / 0.5 \% \mathrm{NP}-40 / 1.5 \mathrm{mM} \mathrm{MgCl}_{2}$ ) by vortexing and centrifuged at $13,000 \times g$ for $20 \mathrm{~min}$ at $4{ }^{\circ} \mathrm{C}$. Supernatants were cleaned using pre-immune rabbit sera to remove any non-specific reaction and then incubated with primary antibody against PfAB4 diluted 1:200 for overnight under gentle rotation $(15 \mathrm{rpm})$ at $4{ }^{\circ} \mathrm{C}$. Dynabeads ${ }^{\circledR}$ protein A or G (Invitrogen) washed three times in cell lysis NP-40 buffer were added into the lysate-antibody mixture and incubated at room temperature for $2 \mathrm{~h}$ with gentle rotation. Beads containing antibody-antigen complexes were washed three times in NP-40 buffer using magnetic isolation and reacted proteins were eluted from beads by adding $2 \mathrm{D}$ gel-electrophoresis buffer, vortexed, centrifuged and subjected to 2D gel electrophoresis.

\section{Protein in-gel digestion, phosphopeptide enrichment, nanoflow LC/MS/MS analysis and database searching}

Spot picking of interesting proteins in 2D gels was guided by immunoblot images on duplicate gels. Immunoprecipitated samples were stained with Coomassie blue and the most abundant spots were picked. In-gel digestion was performed as described below: the excised protein spot was put into an Eppendorf Ultra-Pure $1.5 \mathrm{ml}$ centrifuge tube. The band was then cut into 1-cubic $\mathrm{mm}$ cubes and rinsed twice in $200 \mu \mathrm{l}$ MilliQ water for $15 \mathrm{~min}$. The gel slices were dehydrated by the addition of $100 \mu \mathrm{l}$ of $50 \%(\mathrm{v} / \mathrm{v})$ acetonitrile/water and incubated at room temperature for $10 \mathrm{~min}$. One-hundred $\mu \mathrm{l}$ of ammonium bicarbonate $(50 \mathrm{mM})$ was then added to each sample and incubated again at room temperature for $10 \mathrm{~min}$. These last two steps were repeated. After removal of the ammonium bicarbonate, $10 \mu \mathrm{l}$ of sequence grade trypsin (Promega Southampton, UK) $\left(10 \mu \mathrm{g} \mathrm{ml}^{-1}\right.$ in $50 \mathrm{mM}$ ammonium bicarbonate) was then added to the gel fragments and incubated at $37^{\circ} \mathrm{C}$ for $15 \mathrm{~h}$ (overnight), after which the supernatant was removed and kept. Twenty $\mu \mathrm{l}$ of $70 \%$ acetonitrile ( $\mathrm{v} / \mathrm{v}$ in water) was added to the gel and incubated for $10 \mathrm{~min}$ at room temperature. The supernatant was then removed and pooled with the previous supernatant. The combined supernatant was dried in a speed-vac, re-suspended in $12 \mu \mathrm{l}$ of $0.1 \%$ formic acid.

The trypsin-digested peptide sample or phosphopeptides, enriched by Magnetic Titanium Dioxide Phosphopeptide Enrichment kit (Pierce) according to manufacturer's instructions, was centrifuged at 13,000 $\times g$ for $15 \mathrm{~min}$ to remove any insoluble material. The supernatant was placed in a new tube and diluted using $0.1 \%$ $(\mathrm{v} / \mathrm{v})$ formic acid according to loading requirements. For LC-MSMS analysis: peptides were initially separated by reverse-phase chromatography using a DIONEX UltiMate $^{\mathrm{TM}}$ 3000LC chromatography system. For MS proteomics, $10 \mu \mathrm{l}$ of peptides were injected onto a $\mathrm{C} 18$ reverse-phase column [ $2 \mu \mathrm{m}$ particle size (100), $75 \mu \mathrm{m}$ diameter $\times 150 \mathrm{~mm}$ long] at nanoflow rate $\left(0.3 \mu \mathrm{l} \mathrm{\textrm {min } ^ { - 1 } )}\right.$ and separated over linear chromatographic gradients. The gradients employed for chromatographic separation were composed of buffer A (2.5\% acetonitrile: $0.1 \%$ formic acid) and buffer B (90\% acetonitrile: $0.1 \%$ formic acid). For in-gel proteolysis we employed a 60-min linear chromatographic gradient. Following chromatographic separation, MS analysis was performed on an LTQ Orbitrap Velos mass spectrometer using Xcalibur (version 2.1) software (Thermo Scientific, UK). Ions were scanned between $350-2000 \mathrm{~m} / \mathrm{z}$ in positive polarity mode. The ion-trap operated with CID MS/MS (with wide band activation) on the 20 most intense ions. Dynamic exclusion was enabled to avoid repeatedly selecting intense ions for fragmentation and this was set at 500 with an exclusion duration of $20.0 \mathrm{~s}$. Charge states of 1 were rejected. The minimum MS signal threshold was set at 500 counts and the MS/MS default charge state was 2 with a $1.2 \mathrm{~m} / z$ isolation width, normalized CID at $35 \mathrm{~V}$ and an activation time of $10 \mathrm{~min}$. The resulting MS/MS spectra were submitted to Proteome Discoverer (Thermo Scientific, UK) version 1.2. Searching was against NCBI $P$. falciparum and human databases separately and was performed using fixed carbamidomethyl and variable phosphorylation modifications. Peptide tolerance was set at $0.5 \mathrm{Da}, \mathrm{MS} / \mathrm{MS}$ tolerance was set at $0.1 \mathrm{Da}$. Phosphorylated protein identities were considered significant if the protein score was over the $95 \%$ confidence limit and at 
least one phosphorylated site was unambiguously identified when a phosphorylated residue existed (matched) $y$ - or b-ions in the peak lists of the fragment ions [providing evidence of observed neutral loss of $\mathrm{H}_{3} \mathrm{PO}_{4}$ from the precursor or identified intact phosphorylated residues of serine $(\mathrm{pS})$, threonine $(\mathrm{pT})$ and tyrosine $(\mathrm{pY})$ ]. If the protein score reached a significant level but the ion score of phosphorylated peptide was under the $95 \%$ confidence limit, these were referred to as potential-phosphorylated proteins.

\section{Results}

Using ten commercial antibodies to five different signalling transduction pathways, only one positive molecule from $P$. falciparum parasites was identified with an antimammalian phospho-ІкВ $\alpha$ antibody, with a molecular weight (34 kDa) (Additional file 1). This molecule was named PfAB4 and further characterization of PfAB4 in several $P$. falciparum laboratory parasite lines was undertaken.

According to PlasmoDB, there is no IкB and other components of the NFKB pathway in Plasmodium parasites. By immune blot using this antibody, we found that PfAB4 is a $34 \mathrm{kDa}$ protein expressed at the asexual stage of $P$. falciparum, the expression peak starts at $30 \mathrm{~h}$ after invasion and lasts to late schizont stages (up to $44 \mathrm{~h}$ ); at the early ring stage the expression level was low (Fig. 1a). Calf intestinal alkaline phosphatase (CIP) treatment of $\mathrm{pRBC}$ lysates from several parasite strains decreased their expression of the PfAB4 epitope, indicating that PfAB4 is a phosphorylated protein (Fig. 1b). There is also a phosphorylated $90 \mathrm{kDa}$ protein reacting with $\mathrm{AB} 4$ antibodies but lacking stimulation responses, therefore work in this paper mainly focused on the $34 \mathrm{kDa}$ PfAB4 protein.

The second feature is the inducible nature of PfAB4 epitope. This was seen as a rapid turnover and early (immediate) response to several stimuli such as osmolality change, serum depletion/addition and cytokine stimulation. This was a reversible process which is recovered within several hours. For example, TNF induced a loss of the PfAB4 signal, presumably due to dephosphorylation/degradation, in several parasite strains (Fig. 2). This phenomenon was detectable after 2 min of treatment with TNF, while at 60-min incubation the level of this epitope was almost back to the original $(0 \mathrm{~min})$ signal. The response to osmolality is shown in Additional file 2.

The third feature is that different parasite strains have different expression levels of the PfAB4 epitope, with

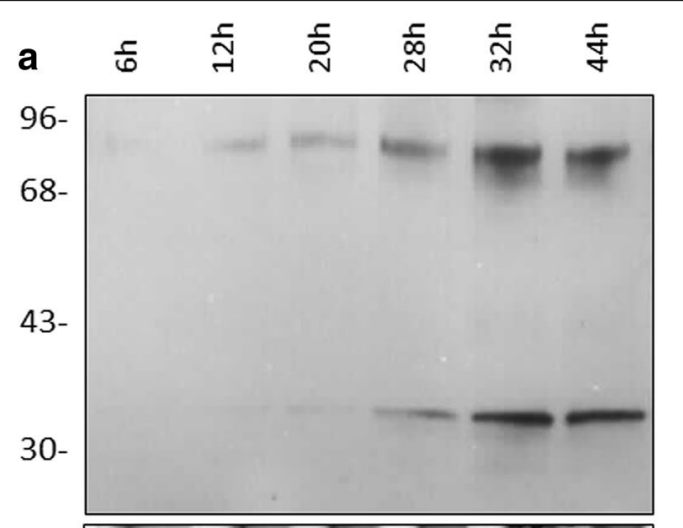

b
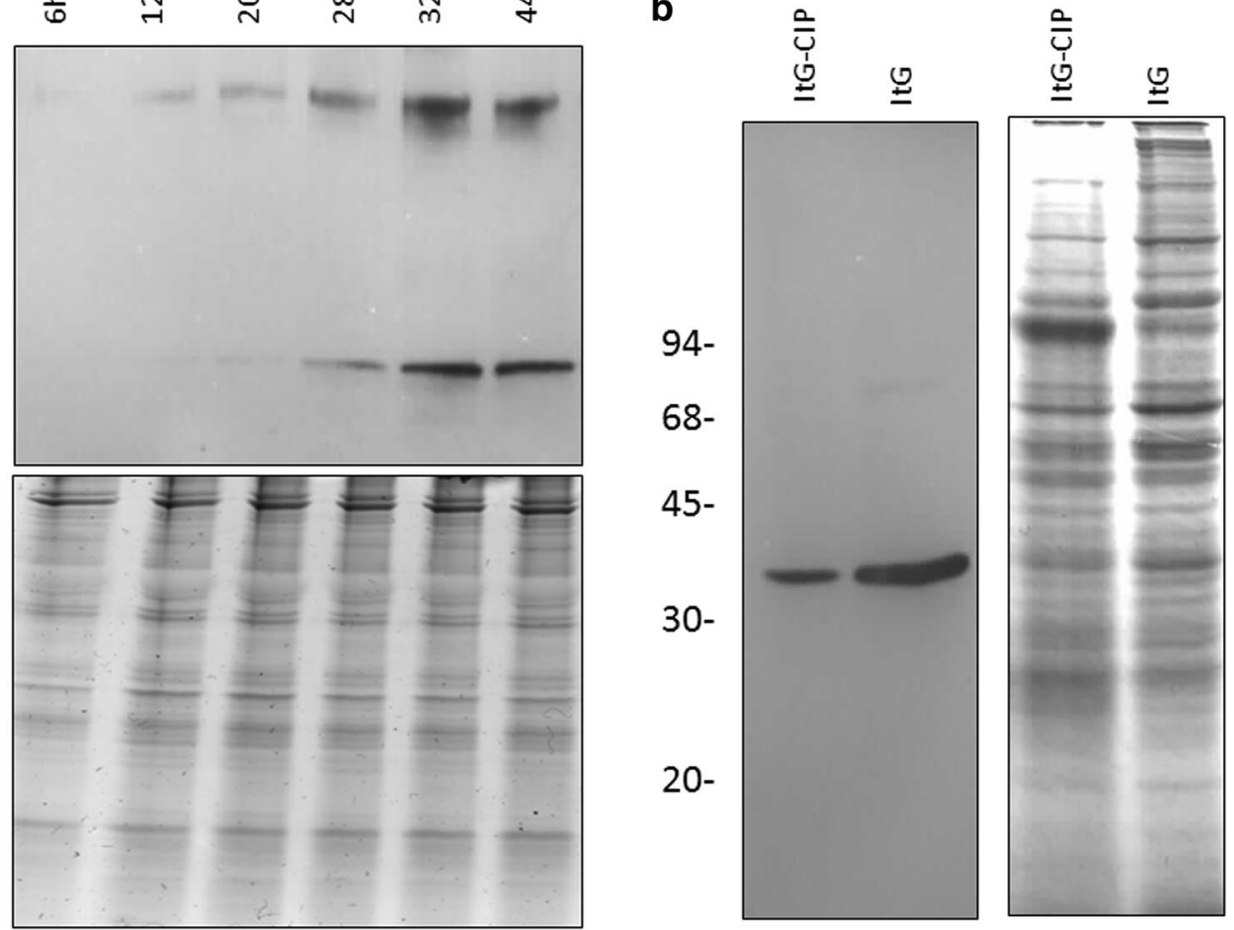

Fig. 1 Synchronized stage specific ItG parasite lysates at 14,24,36 and $46 \mathrm{~h}$ after parasite invasion were analysed by Western blot using AB4 antibodies. PfAB4 expressed throughout parasite lifecycle with expression peak between 28 and $32 \mathrm{~h}$. A 90 kDa protein also reacted with AB4 antibodies. The lower part is the Coomassie blue stained gel image used as loading control (a). Pane/ b shows parasite strains with CIP in vitro treatment, which attenuated the signal indicating the phosphorylation state of PfAB4 proteins 


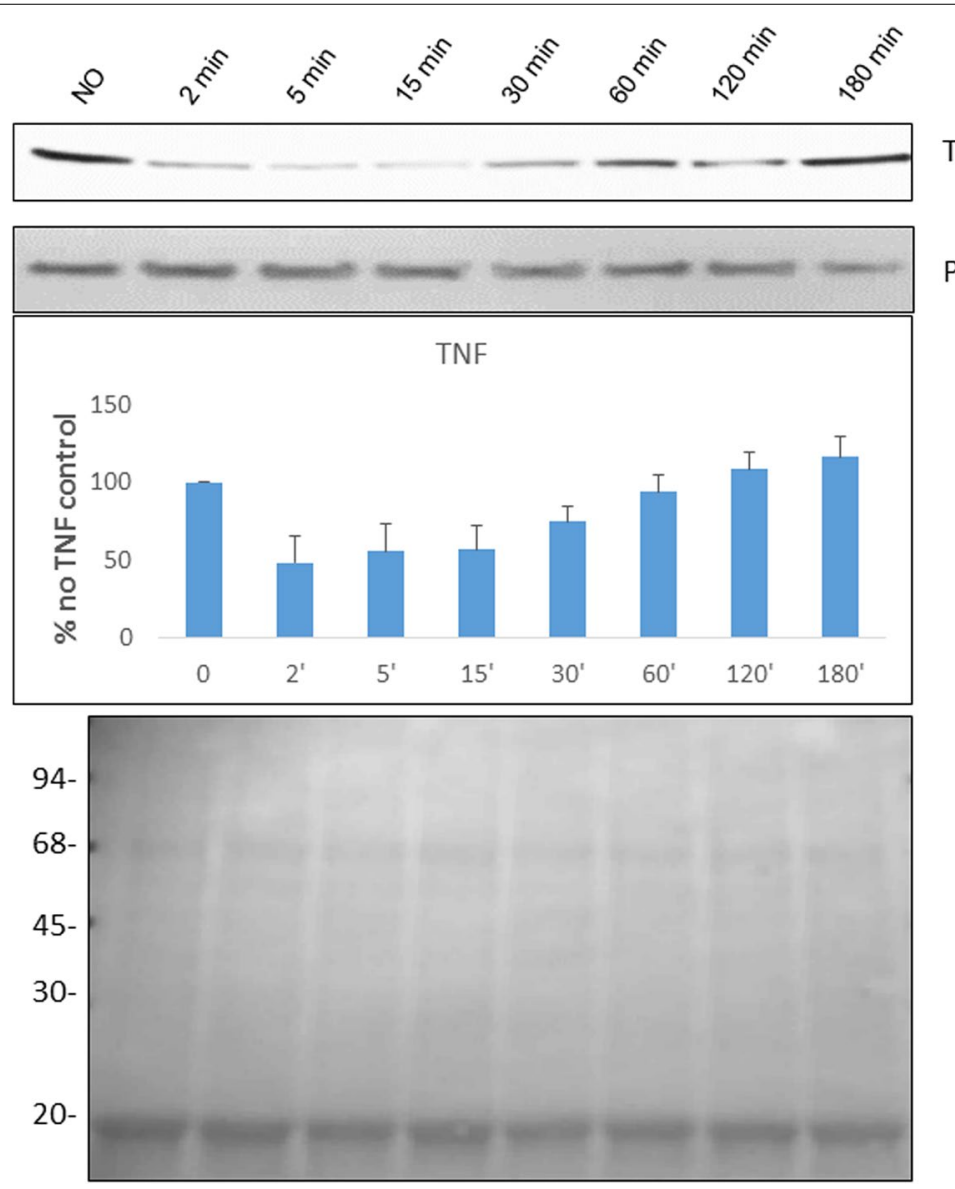

Fig. 2 ItG parasites at mid-trophozoite stage were exposed to TNF $\left(1 \mathrm{ng} \mathrm{ml}^{-1}\right)$ treatment for 2, 5, 15, 30, 60, 120 and 180 min. PBS mock treatment was performed as a control. The expression of PfAB4 from total cell lysates was determined by Western blot using AB4 antibodies (upper panel). The middle panel shows the quantification of PfAB4 level from three independent experiments by scanning autoradiographs. The lower panel shows a Coomassie blue stained image as a loading control

the levels ranging from high expression to almost absent expression (Fig. 3). To confirm that this profile is not caused by the variation in stage-specific expression, the expression levels of PfAB4 in both high expression and low expression parasite strains were measured at time points throughout intra-erythrocyte development cycle (IDC). The strains of Dd2, BC12 and PCM7 showed consistently low expression at all stages, while ItG, 3D7 and A4 demonstrated high PfAB4 expression during the IDC. Biochemical fractionation showed that the PfAB4 protein in low expression parasite strains, such as $\mathrm{Dd} 2$, was only detected in the parasite cytosol and no changes were seen during IDC development (Additional file 3).

To understand if this difference was at the transcriptional level conventional RT-PCR was carried out for the strains with known PfAB4 expression level, but the results were inconsistent, therefore, qRT-PCR was carried out to measure the transcript abundance of the candidate genes (based on preliminary MS data) from different parasite strains with known PfAB4 epitope levels. Three independent RT-qPCR experiments were carried out for six parasite strains and five target genes, all results were normalized using internal control and represented as fold change. The most abundant transcript was EXP2, and the least abundant was PCNA2. All strains showed variable patterns of transcription of the genes being tested, but these were not co-incident with known protein levels for PCNA1 and EXP2 (Fig. 4). PCNA1 and EXP2 from both Dd2 and ItG strains (low and high PfAB4 expressers, respectively) have been cloned and there were no sequence differences in pcnal between the two strains, although there was a deletion mutation difference in $\exp 2$ between Dd2 and ItG strains.

To view better the expression profiles of PfAB4 under TNF stimulation in terms of localization, a combined method of saponin lysis and detergent nuclear extraction was used to separate ItG proteins into $\mathrm{pRBC}$ ghost, parasite cytosol, nuclear, and insoluble fractions. 


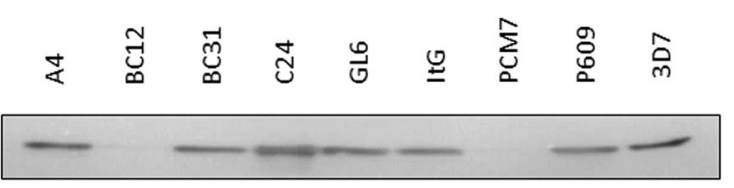

mAb AB4

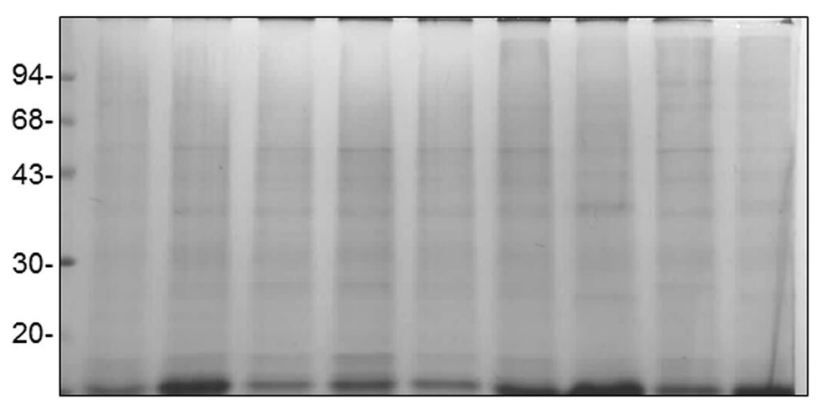

Stained gel

(loading

control)

Fig. 3 Different parasite strains have different expression levels of PfAB4. The total protein lysates were extracted from ten well-synchronized parasite strains and analysed for PfAB4 expression level. Dd2, BC12 and PCM7 were repeatedly identified as low expression strains. The lower panel shows the Coomasie blue stained image used as a loading control

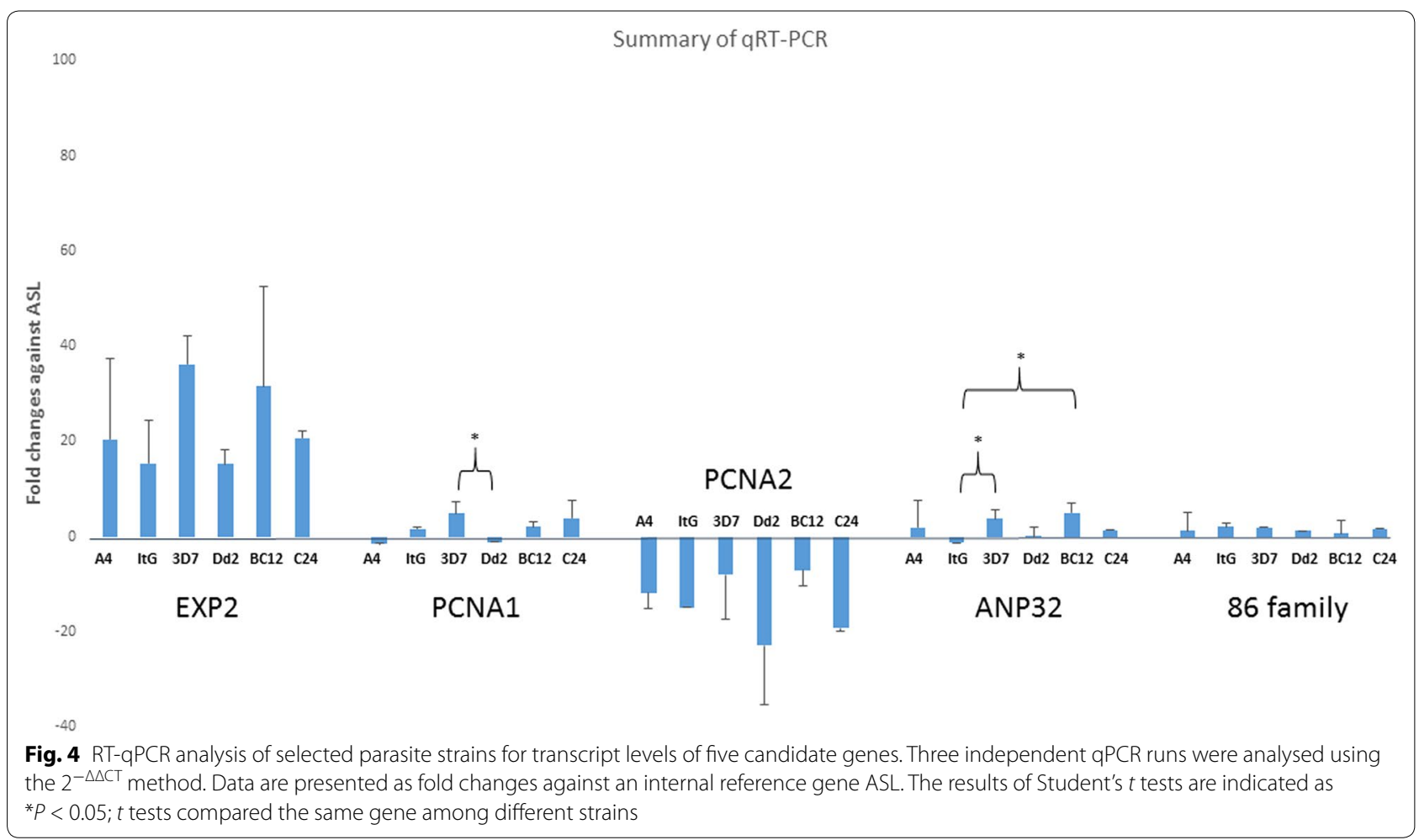

These four fractions were then subjected to either 1D SDS-PAGE or 2D gel electrophoresis followed by immune-blot using the $\mathrm{AB} 4$ antibody. As indicated by fractionation, 1D SDS-PAGE and immuno-blotting (Fig. 5), PfAB4 is localized both in parasite cytoplasm and nucleus. Interestingly, this epitope was able to shift between the cell compartments under TNF treatment such that for 10-30 min it migrated from cytosol and insoluble fractions to the nucleus. At $60 \mathrm{~min}$ it was seen to accumulate back in the cytosol and insoluble fractions. No PfAB4 was detected in the pRBC ghost fraction. 


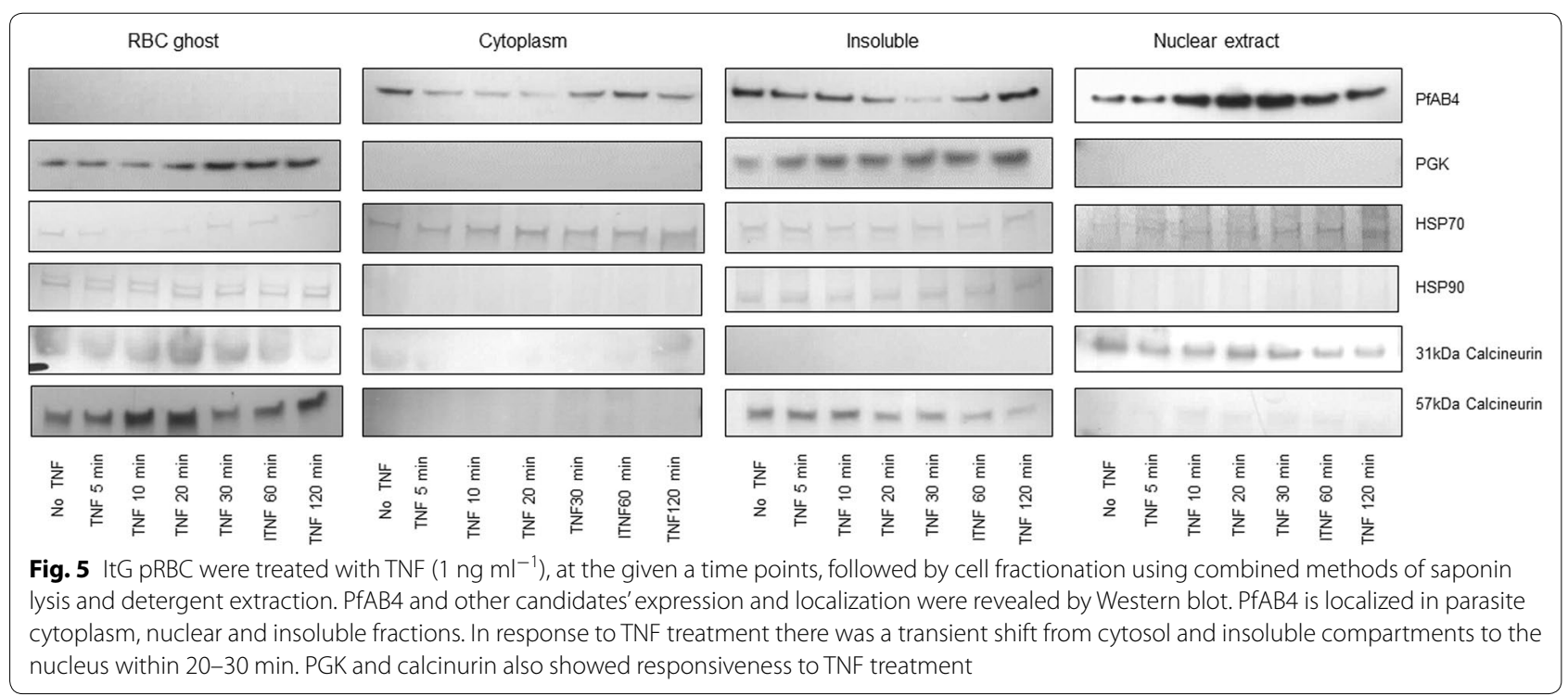

In response to TNF stimulation, PfAB4 molecules not only shifted from one compartment to another, but they also changed their isoelectric point (PI). To further analyse these changes, $2 \mathrm{D}$ gel strips with a narrow $\mathrm{pH}$ range of 3.9-4.9 were used to separate PfAB4 isoforms at several time points after TNF treatment. Shown in Western blots in Fig. 6, PfAB4 isoform shifting in the nucleus was from $\mathrm{pH}$ 4.9-4.5, moving from basic to acidic direction, while in the cytosol, the PI of PfAB4 isoform showed minor shifts within the range $\mathrm{pH} 4.5-4.9$, from acidic to basic direction (Fig. 6).

One-hundred and $200 \mu \mathrm{M}$ calpeptin (a calpain inhibitor) treatment $1 \mathrm{~h}$ before TNF activation caused a block in the degradation of PfAB4 after stimulation with TNF
(Fig. 7), suggesting that changes in expression of PfAB4 might be the result of a ubiquitin-independent pathway and subsequent degradation by a proteasome complex, as previously suggested in other systems by inhibition experiments with peptide aldehyde inhibitors of the proteasome, such as calpain inhibitor I [34, 35]. Gambogic acid is an important anti-cancer drug candidate, a natural product inhibitor of HSP90, which inhibits heat shock protein 90 and down-regulates $\mathrm{TNF} / \mathrm{NF} \mathrm{BB}$. It has been shown that Gambogic acid physically binds to HSP90, inhibiting its ATPase activity and leads to degradation of HSP90 client proteins (i.e., Akt, IKK) in HeLa cells [36]. In this study, overnight pre-treatment with Gambogic acid (0.5, 1.0 and $1.5 \mu \mathrm{M})$ not only inhibited the

\section{Cytoplasm}

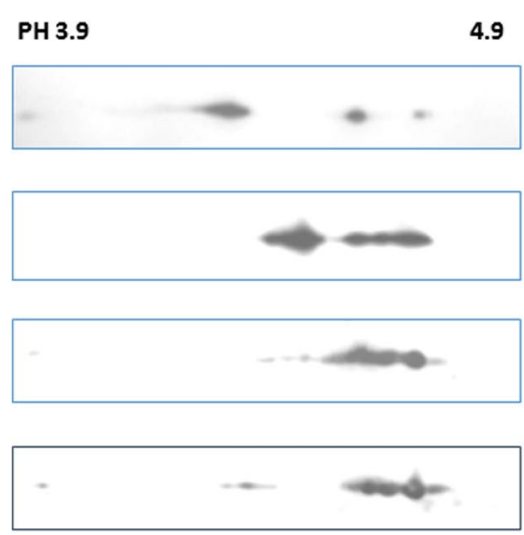

\section{Nucleus}

PH 3.9

4.9

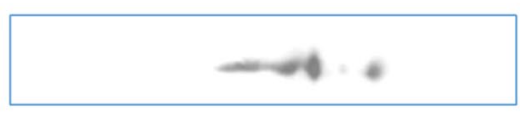

$\mathrm{ItG} / \mathrm{TNF} 5 \mathrm{~min}$

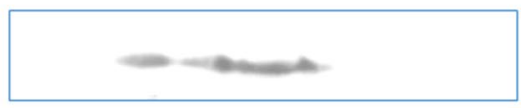

ItG / TNF 10min

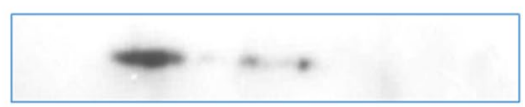

ItG / TNF 30min

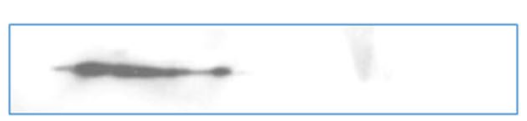

Fig. 6 Proteins from cytoplasmic and nuclear fractions of ItG pRBC before or after TNF $\left(1 \mathrm{ng} \mathrm{ml}^{-1}\right)$ treatment at the four time points were subjected to 2D gel electrophoresis using narrow pH (3.9-4.9) immobiline Drystrips. PfAB4 expression was revealed by Western blot, showing different patterns of migration in the nucleus and cytoplasm over time 


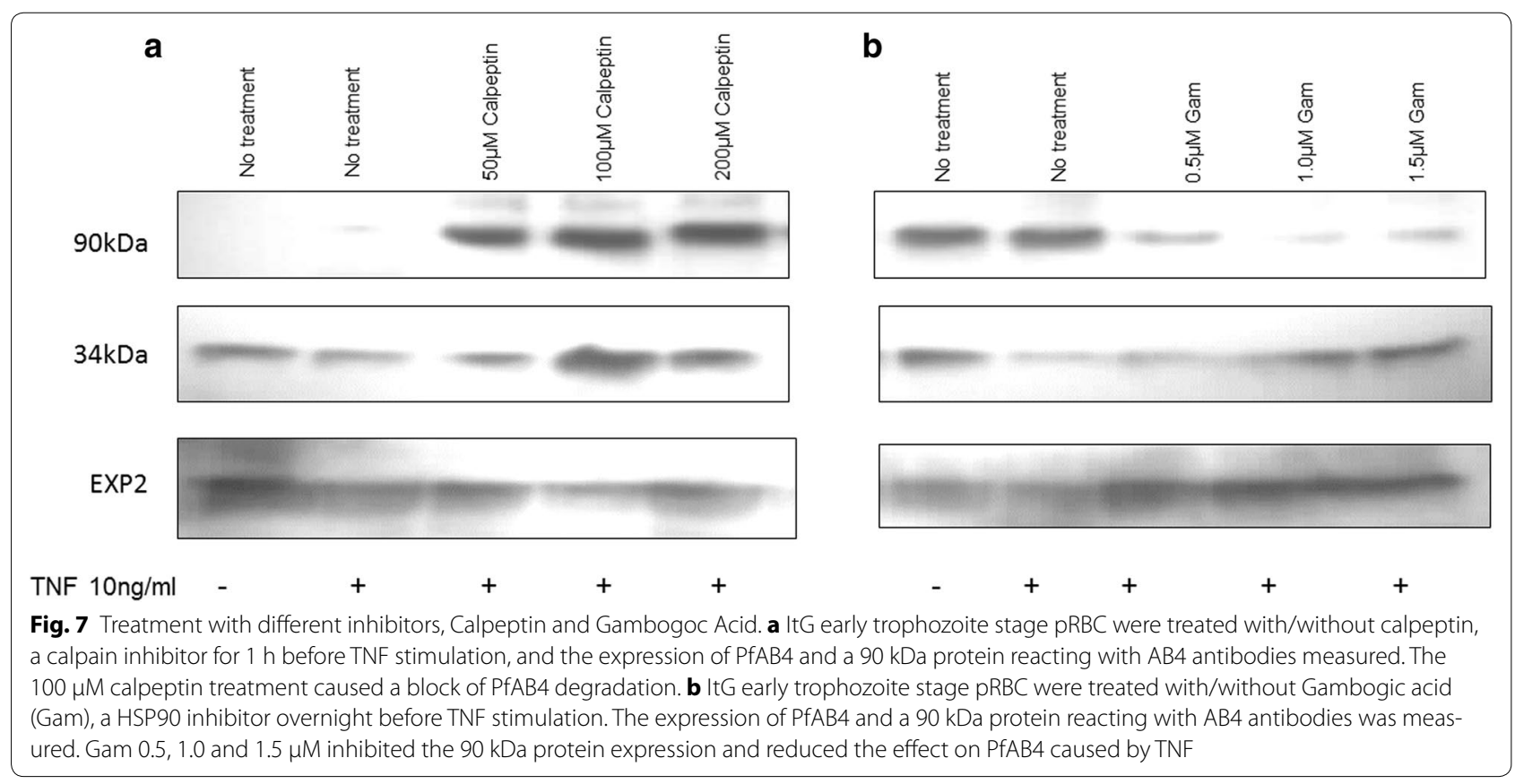

expression of $90 \mathrm{kDa} A B 4$-associated protein, but also abrogated the effects of TNF on $34 \mathrm{kDa}$ PfAB4 expression (Fig. 7) suggesting that AB4 antibody recognized $90 \mathrm{kDa}$ protein could be a member of HSP90 family and that $34 \mathrm{kDa}$ PfAB4 may be associated with HSP90.

There were a number of proteins with sizes around $34 \mathrm{kDa}$ as seen by staining and immunoblots with different antibodies, and intensive methods have been used to biochemically separate PfAB4 protein using, for example, different gel concentrations, buffer systems and gel types. The best and the most reproducible technique was with 2D electrophoresis separating immune precipitants from IP/Co-IP by AB4 antibodies. This allowed the specific separation of the target proteins and their associates. The $34 \mathrm{kDa}$ reaction spot contains in very close proximity or overlapping, a mixture of PCNA1 and EXP2 along with a small number of other inconsistently identified peptides. A $90 \mathrm{kDa}$ protein was also immuno-precipitated/ co-immunoprecipitated with IDs of HSP86 and HSP70 (Table 2).

To confirm the phosphorylation states of the target protein and to identify the phosphorylated peptides in target proteins, a Titanium Dioxide Phosphopeptide Enrichment kit (Pierce) was used to pull down the phosphorylated peptides after 1D SDS-PAGE separation and trypsin in-gel digestion, from both low and high PfAB4 expression parasite strains, Dd2 and ItG. The resulting trypsinized peptides were subsequently subjected to Orbitrap MS analysis, with the results shown in Table 3. The phosphorylated peptides of PCNA1 were only found

\section{Table 1 Primer sequences for qRT-PCR analysis}

\begin{tabular}{ll}
\hline Name & Primer sequences \\
\hline PCNA1 & Forward: 5' AGTAGGTGATGCTGAAGTAGC 3' \\
& Reverse: 5' CCTAAGACAACGACATCTGCT 3' \\
PCNA2 & Forward: 5' AGGTGTGATAAAAATTGCGTT 3' \\
& Reverse: 5' TCGTCAGCACTTGATTGTTC 3' \\
EXP2 & Forward: 5' AGATGGTCACGTATGTGGTG 3' \\
& Reverse: 5'TGGTTTGGATTCTACGGCAT 3' \\
HSP86family & Forward: 5' ACCAAGAAGAGGAGAAGTTGG 3' \\
& Reverse: 5' GCTCTTTGTTCTTCTGCACT 3' \\
ANP32 & Forward: 5' ACAGACCTTAGAAAATATCCCATCA 3' \\
& Reverse: 5' TGGTTTCCACCTATTTCAAGGG 3' \\
\hline
\end{tabular}

in ItG and not Dd2, and there were no EXP2 peptides. Therefore the Plasmodium protein recognized by antibody to human phospho-IкB- $\alpha$ antibody (AB4) is likely to be PfPCNA1. These experiments enabled us to identify triple phosphorylation sites in the PfAB4 epitope at serine 87, serine 91 and serine 92 in PCNA1 (Fig. 8).

\section{Discussion}

The intention of this work was to look for parasite signalling molecules and understand how malaria parasites might sense the host environment. To exist in a wide range of environmental niches, organisms must sense and respond to a variety of external signals.

A primary means by which external sensing occurs in bacteria is through two-component signal transduction 
Table 2 Mass spectrometry identifications of AB4 immnoprecipitated material

\begin{tabular}{|c|c|c|c|c|}
\hline Accession No. & Description & MW & PI & Score \\
\hline \multicolumn{5}{|c|}{ The low molecular weight 34kDa PF-proteins from IP with AB4 antibody } \\
\hline gi3021540 & Exported protein 2 & 32.9 & 4.87 & 455 \\
\hline gi124513948 & Proliferating cell nuclear antigen 1 & 30.9 & 4.78 & 167 \\
\hline gi160537 & Surface protein & 27.6 & 5.12 & 148 \\
\hline gi111034851 & L-lactate dehydrogenase & 34.0 & 7.55 & 143 \\
\hline gi296005038 & 14-3-3 protein & 30.2 & 4.92 & 140 \\
\hline gi124512500 & -binding protein a & 27.2 & 10.58 & 96 \\
\hline gi124512686 & Proteasome beta-subunit & 30.9 & 6.44 & 80 \\
\hline gi124806227 & Proliferating cell nuclear antigen 2 & 30.1 & 4.68 & 46 \\
\hline \multicolumn{5}{|c|}{ The high molecular weight 90kDa PF-proteins from IP with AB4 antibody } \\
\hline gi124506906 & Heat shock protein 70 & 72.3 & 5.31 & 339.91 \\
\hline gi124506155 & $\begin{array}{l}\text { Myo-inositol 1-phosphate synthase, } \\
\text { putative }\end{array}$ & 69.1 & 7.4 & 119.2 \\
\hline gi124511730 & Heat shock protein 86 & 86.1 & 5.01 & 109.85 \\
\hline gi124512406 & $\begin{array}{l}\text { Heat shock } 70 \text { kDa protein homo- } \\
\text { logue }\end{array}$ & 71.5 & 6.09 & 62.36 \\
\hline gi124513604 & Kelch protein, putative & 83.6 & 5.67 & 164.86 \\
\hline gi124512982 & $\begin{array}{l}\text { Vacuolar ATP synthase, catalytic } \\
\text { subunit a }\end{array}$ & 68.6 & 4.98 & 117.28 \\
\hline gi258597535 & Chaperonin, cpn60 & 81.4 & 5.11 & 42.84 \\
\hline gi124802912 & $\begin{array}{l}\text { Erythrocyte membrane protein, } \\
\text { putative }\end{array}$ & 80.2 & 4.98 & 113.77 \\
\hline
\end{tabular}

pathways, typically composed of a sensor histidine kinase that receives the input stimuli and then phosphorylates a response regulator that effects an appropriate change in cellular physiology. The sensing system described in this paper could be part of a two-component signal transduction pathway in $P$. falciparum, which would be the first time such a system has been recognized and reported. The results indicate that PCNA1 is most likely a component of this sensing system. PCNA1 is an auxiliary protein of DNA polymerase-delta, forms a trimer ring around a DNA double-helix and is a member of the DNA sliding clamp family [37]. It is absent or present in very low amounts in normal non-dividing cells and tissues, but synthesizes in variable amounts by proliferating cells $[38,39]$.

Phosphorylation/dephosphorylation, ubiquitination, sumoylation, and acetylation have all been described for nuclear PCNA and offer a range of options to modulate PCNA activities [40]. Post-translational modification of cytosolic PCNA has been assumed as a key factor in neutrophil survival. Neutrophils express high levels of PCNA localized exclusively in cytosol, which is ubiquitinated and degraded via the proteasome during apoptosis. Furthermore, PCNA nuclear to cytoplasmic delocalization at the end of granulocyte differentiation has also been demonstrated [41, 42]. These post-translational modifications of PCNA may be crucial in influencing the cellular choice between different pathways, such as the cell cycle checkpoint, DNA repair or apoptosis in order to maintain genomic stability. A recent study has shown that both Pf-PCNA1 and Pf-PCNA2 participate in an active DNA-damage-response pathway with significant accumulation in the parasite upon DNA damage induction, but Pf-PCNA-mediated regulation was not at the level of transcription, but presumably at the protein stability level [43]. It has been suggested by this study that one feature of regulation is via post-translational modification, and that phosphorylation/dephosphorylation controls some functions of Pf-PCNA1.

Tumour necrosis factor (TNF) is a pro-inflammatory cytokine that plays a critical role in diverse cellular events, including cell proliferation, differentiation, and apoptosis. Following stimuli by pro-inflammatory cytokines such

Table 3 Mass spectrometry identifications from phospho-peptide enrichment

\begin{tabular}{|c|c|c|c|c|}
\hline & Dd2 before enrichment & Dd2 after enrichment & ItG before enrichment & ItG after enrichment \\
\hline $34 \mathrm{kDa} /$ no treatment & $\begin{array}{l}\text { Heat shock } 70 \text { kDa } 187 \\
78 \text { kDa glucose-regulated } \\
\text { protein }\end{array}$ & $\begin{array}{l}\text { Elongation factor 1-alpha mero- } \\
\text { zoite surface protein P12 } \\
\text { Putative E3 ubiquitin-protein } \\
\text { ligase protein }\end{array}$ & - Heat shock 70 kDa protein & $\begin{array}{l}\text { Proliferating cell nuclear } \\
\text { antigen }\end{array}$ \\
\hline $34 \mathrm{kDa} / \mathrm{TNF}$ & $\begin{array}{l}\text { Fructose-bisphosphate aldolase } \\
\text { Aspartic acid-rich prot } \\
\text { Plasmepsin-1 } \\
\text { Plasmepsin-2 } \\
\text { Ornithine aminotransferase }\end{array}$ & $\begin{array}{l}\text { Elongation factor } 1 \text {-alpha } \\
\text { Merozoite surface protein P12 } \\
\text { Dynein heavy chain-like protein }\end{array}$ & $\begin{array}{l}\text { Acidic leucine-rich nuclear } \\
\text { phosphoprotein 32-related } \\
40 \text { S ribosomal protein S3a } \\
\text { Proliferating cell nuclear } \\
\text { antigen } \\
\text { L-lactate dehydrogenase } \\
\text { Aspartic acid-rich protein }\end{array}$ & $\begin{array}{l}\text { Glyceraldehyde-3-phosphate } \\
\text { dehydrogenase } \\
\text { Aspartic acid-rich protein } \\
\text { Apolipoprotein E }\end{array}$ \\
\hline 70 kDa & $\begin{array}{l}\text { Knob-associated histidine-rich } \\
\text { protein }\end{array}$ & $\begin{array}{l}\text { Reticulocyte-binding protein } 3 \\
\text { Dynein heavy chain-like protein } \\
\text { Reticulocyte-binding protein } 2 \\
\text { MATH and LRR domain-contain- } \\
\text { ing protein } \\
\text { Putative E3 ubiquitin-protein } \\
\text { ligase protein }\end{array}$ & $\begin{array}{l}\text { Knob-associated histidine-rich } \\
\text { protein } \\
101 \text { kDa malaria antigen } \\
\text {-Probable cathepsin C } \\
\text { Heat shock } 70 \text { kDa protein } \\
78 \text { kDa glucose-regulated } \\
\text { protein homologue }\end{array}$ & $\begin{array}{l}\text { Knob-associated histidine-rich } \\
\text { protein }\end{array}$ \\
\hline
\end{tabular}




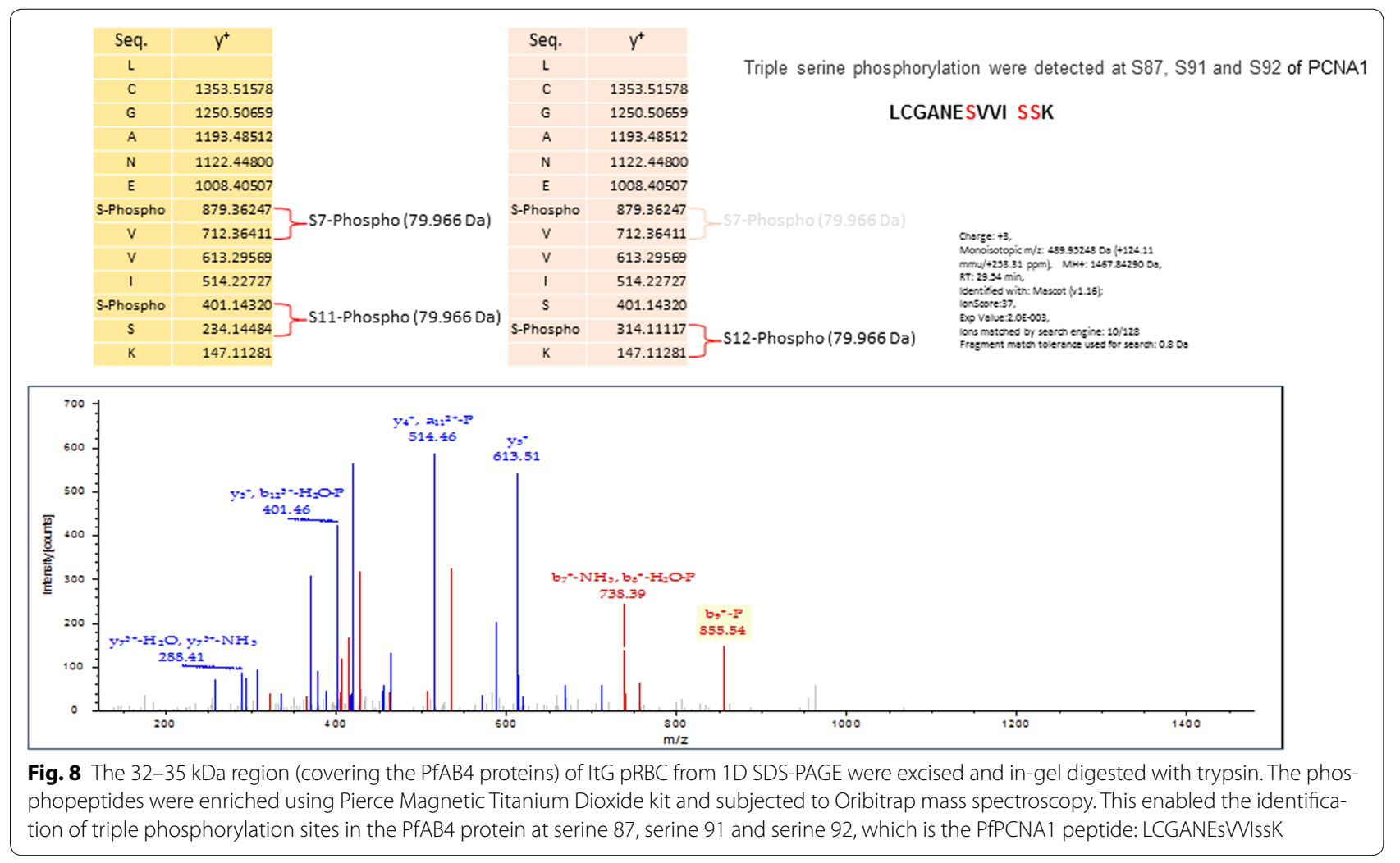

as TNF and interleukin-1, IkBs are phosphorylated by IkB kinase (IKK) in mammalian species resulting in their rapid, proteasome-dependent degradation $[44,45]$. IkBs are regulatory proteins that inhibit NFkB by complexing with and trapping it in the cytoplasm. They are involved in events including cell adhesion, immune and pro-inflammatory responses, apoptosis, differentiation, and growth. Although this machinery is not thought to exist in Plasmodium parasites, an analogous system may have evolved to detect this important host protein. Signal transduction regulation inside Plasmodium has been shown as a major mechanism to control parasite development [15]. In the mammalian host, studies have shown that TNF induces extensive alterations in host microvascular endothelium, including morphological re-organization [46], release of membrane microparticles [47], production of other proinflammatory cytokines, up-regulation of receptors and apoptosis $[48,49]$. Interestingly, inhibitors of TNF production reduced infected erythrocyte cytoadherence [50, 51]. However, TNF signalling in the Plasmodium parasite itself has not been previously reported, therefore, understanding the mechanisms of sensing TNF stimulation seen in this study could improve the molecular description of how Plasmodium adapts to its host environment.

In a parallel study looking for TNF effects on parasite calcium-dependent signalling, the work showed the ability of the parasite to increase intracellular calcium concentration after exposure to TNF, thus corroborating the hypothesis of an external sensing system allowing the parasite to sense the environment (Cruz et al., unpublished data). This behaviour is also linked to the parasite synchronicity to host circadian rhythms [52] being previously shown that the parasite cell cycle can be modulated by external signals such as melatonin and products of tryptophan catabolism, leading to intracellular calcium increase thought a PLC-IP3 mechanism [53-55]. Plasmodium is also able to sense external ATP through rise in cytosolic calcium $[15,56]$. Moreover, evidence has also been provided for $\mathrm{K}^{-} / \mathrm{Ca}^{2+}$ signalling mechanisms in $P$. falciparum [57].

The pRBC ghosts contain haemoglobin-depleted erythrocyte material that has lost most of its internal proteins, therefore, this fraction represents an enriched erythrocyte membrane compartment containing molecules attached/ associated with the membrane. Parasite-encoded membrane proteins translocated to the surface of infected erythrocytes or in specialized vesicles underneath (Maurer's clefts), play a key role in the asexual lifecycle. How might all these membrane proteins fit together in the parasite's 'sensing apparatus'? Many studies have reported that heat shock proteins HSP70 and HSP90 regulate a number of signalling cascades to maintain cellular 
homeostasis several species $[58,59]$. Recent studies have revealed that HSP70 and HSP90 proteins regulate the function of the IKK complex, which is the major activator of the NF- $\kappa B$ complex [60]. It has been shown that the histidine kinase auto-phosphorylates in the presence of an intra-or extra-cellular environment stimulus or stress, which could be one of the triggers. HSP90 plays an important role in TNF-mediated NF-kB activation by modulating the stability and solubility of receptor interacting protein (RIP) [61]. In this study, antibody $A B 4$ recognized a $90 \mathrm{kDa}$ protein consistent with being HSP90, which was supported by Western blot with an anti-HSP90 antibody (Additional file 4). This was also confirmed by coimmunoprecipitation followed by mass spectrum. HSP90 inhibitor Gambogic acid not only inhibited the expression of this $90 \mathrm{kDa}$ protein, but also abrogated the effects of TNF on PfAB4. This suggests that PfPCNA1 may be one of the HSP90 client proteins, which may explain its identification by AB4 immuno-precipitation and co-migration in the gel electrophoresis. Such an association has been reported previously in several cancer cell lines [62]. The proteins in the insoluble fraction are probably cell membrane components or have high affinity binding to the cytoskeleton, and these potentially could be the 'perception proteins' of $\mathrm{pRBC}$. Although data are incomplete they suggest, for the first time, a link between PCNA1 and HSP90 in a parasite sensing system.

An attempt was made to investigate the outcome of the TNF regulatory mechanism of $P$. falciparum parasite strains by analysing transcriptomes of the 3D7 and $\mathrm{Dd} 2$ strains (representing high and low PfAB4 phenotypes) with and without TNF treatment by RNAseq analysis. A remarkable conservation of the normal transcriptional programme between these strains has previously been observed [63]. The results showed no transcriptional differences associated with TNF treatment. This suggests that post-transcriptional mechanisms may drive the signalling processes and changes to the global transcription pattern in the parasite may only occur in subsequent cycles, which was not investigated. Indeed it is tempting to speculate that changes in var gene expression might be linked to the TNF status in the host to align with altered host adhesion profiles, and might not be detected until one or more cycles after exposure of pRBC to this cytokine.

The cell cycle checkpoints are signal transduction pathways that respond to damaged DNA by inhibiting cell cycle progression [64]. The post-translational modifications of PCNA are considered to be the most relevant during the $\mathrm{S}$ phase cell cycle checkpoint (surveillance system) [65]. PCNA interacts with several eukaryotic cell cycle proteins, binds to cyclin-CDK complexes [66] and CDK inhibitor p21 [67, 68]. PCNA forms complexes with critical checkpoint proteins, transducing both positive and negative signals [69]. It is possible that cell cycle checkpoints may serve as switch points for choosing between cell proliferation and apoptosis, or even have a broader role in parasite replication. The ability to sense the external environment and, for example, move a proportion of the population into a quiescent phase could be beneficial to the parasite in avoiding killing by drugs and a protein such as PfPCNA1 could play a significant role in this.

\section{Conclusion}

This study reported a novel sensing system and some potential regulation mechanisms by which parasites respond to external stimuli including inflammatory cytokines, such as TNF. The sensing and regulating system/rapid responding system in P. falciparum described here might be an equivalent of the two-component regulatory system of bacterial signal transduction. HSP90 could be a component of a membrane-bound histidine kinase that receives the input stimuli from as yet uncharacterized external receptors, and reversible phosphorylated PfPCNA1 could be a response regulator that effects an appropriate change in cellular physiology from this event. This sensing system might also be shared with cell cycle checkpoints, the stimuli which triggered PCNA1 dephosphorylation/degradation may also be implicated in DNA replication stress and damage. Further work is needed to identify the sensor proteins necessary for interacting with specific external signals and the outcomes for the parasite from this system.

\section{Additional files}

Additional file 1. The proteins from normal RBC and ItG pRBC were extracted and separated by SDS-PAG-electrophoresis. The signalling proteins for ten pathways were measured by Western blot. The red arrow indicates the only positive identification of PfAB4. The experiment has been performed independently three times to confirm the results.

Additional file 2. The osmolality of culture reagents used in the laboratory were measured using a pocket OSMOCHECK (PAL-OSMO) (VITECH Scientific Ltd, UK) (A). ItG-pRBC growing in blue (serum containing) medium were placed into Plasmion mix (1:1.5:2.5) for $20 \mathrm{~min}$. Then these pRBCs were centrifuged to change to either blue or yellow (serum-free) medium for 5, 15 and 60 min. The expression of PfAB4 was measured by Western blot (B). The results indicated that transfer from lower osmolality solution to a higher osmolality (blue to 1:1.5:2.5) had no effect on expression of PfAB4, but from higher osmolality solution to a lower osmolality solution (1:1.5:2.5 to blue or yellow) increased the expression of PfAB4.

Additional file 3. The proteins from $\mathrm{Dd} 2$ and ItG $\mathrm{pRBC}$ were extracted at the time points of IDC and separated by SDS-PAG-electrophoresis, followed by Western blot using AB4 antibodies. The results show that the expression of PfAB4 in Dd2 was low (A) and the protein was localized in the cytosol (B).

Additional file 4. ItG-pRBC were treated with $10 \mathrm{ng} / \mathrm{ml}$ TNF for 60, 30, 15 and $5 \mathrm{~min}$ and the cellular proteins were extracted and separated by SDS-PAGE, followed by Western blot probed with anti-HSP90 and AB4 antibodies. The $90 \mathrm{kDa}$ protein recognized by the two antibodies showed similar expression patterns. 


\section{Authors' contributions}

YW, CRSG and AGC designed the study. YW, LNC and TS conducted parasite culture, experimental and laboratory work. YW, GL and GRM conducted mass spectrometric analysis and Bioinformatics. YW, LNC, CRSG, and AGC analysed the data and wrote the manuscript. All authors contributed to the manuscript. All authors read and approved the final manuscript.

\section{Author details}

${ }^{1}$ Department of Parasitology, Liverpool School of Tropical Medicine, Liverpool, UK. ${ }^{2}$ Department of Physiology, Instituto de Biociências, Universidade de São Paulo, São Paulo, São Paulo, Brazil.

\section{Acknowledgements}

This work was supported by The Wellcome Trust (grant reference 095507) and by grants and funding from Fundação de Amparo à Pesquisa (FAPESP process number 2011/51295-5). LNC received a FAPESP Fellowship.

\section{Competing interests}

The authors declared that they have no competing interests.

Received: 4 December 2015 Accepted: 4 February 2016

Published online: 19 February 2016

\section{References}

1. Doerig C, Rayner JC, Scherf A, Tobin AB. Post-translational protein modifications in malaria parasites. Nat Rev Microbiol. 2015;13:160-72.

2. Cohen S, McGregor IA, Carrington S. Gamma-globulin and acquired immunity to human malaria. Nature. 1961;192:733-7.

3. Becker K, Tilley L, Vennerstrom JL, Roberts D, Rogerson S, Ginsburg H. Oxidative stress in malaria parasite-infected erythrocytes: host-parasite interactions. Int J Parasitol. 2004;34:163-89.

4. Rangachari K, Dluzewski A, Wilson RJ, Gratzer WB. Control of malarial invasion by phosphorylation of the host cell membrane cytoskeleton. Nature. 1986;324:364-5

5. Yuthavong Y, Limpaiboon T. The relationship of phosphorylation of membrane proteins with the osmotic fragility and filterability of Plasmodium berghei-infected mouse erythrocytes. Biochim Biophys Acta. 1987;929:278-87.

6. Doerig C, Horrocks P, Coyle J, Carlton J, Sultan A, Arnot D, et al. Pfcrk-1, a developmentally regulated cdc2-related protein kinase of Plasmodium falciparum. Mol Biochem Parasitol. 1995;70:167-74.

7. Bracchi V, Langsley G, Thelu J, Eling W, Ambroise-Thomas P. PfKIN, an SNF1 type protein kinase of Plasmodium falciparum predominantly expressed in gametocytes. Mol Biochem Parasitol. 1996;76:299-303.

8. Li JL, Robson KJ, Chen JL, Targett GA, Baker DA. Pfmrk, a MO15-related protein kinase from Plasmodium falciparum. Gene cloning, sequence, stage-specific expression and chromosome localization. Eur J Biochem. 1996;241:805-13.

9. Lin DT, Goldman ND, Syin C. Stage-specific expression of a Plasmodium falciparum protein related to the eukaryotic mitogen-activated protein kinases. Mol Biochem Parasitol. 1996;78:67-77.

10. Wu Y, Szestak T, Stins M, Craig AG. Amplification of P. falciparum cytoadherence through induction of a pro-adhesive state in host endothelium. PLOS ONE. 2011;6:e24784.

11. Wu Y, Nelson MM, Quaile A, Xia D, Wastling JM, Craig A. Identification of phosphorylated proteins in erythrocytes infected by the human malaria parasite Plasmodium falciparum. Malar J. 2009;8:105.

12. Jenkins N, Wu Y, Chakravorty S, Kai O, Marsh K, Craig A. Plasmodium falciparum intercellular adhesion molecule-1-based cytoadherence-related signaling in human endothelial cells. J Infect Dis. 2007;196:321-7.

13. Tripathi AK, Sha W, Shulaev V, Stins MF, Sullivan DJ Jr. Plasmodium falciparum-infected erythrocytes induce NF-kappaB regulated inflammatory pathways in human cerebral endothelium. Blood. 2009;114:4243-52.

14. Yipp BG, Robbins SM, Resek ME, Baruch DI, Looareesuwan S, Ho M. Src-family kinase signaling modulates the adhesion of Plasmodium falciparum on human microvascular endothelium under flow. Blood. 2003;101:2850-7.
15. Cruz LN, Wu Y, Craig AG, Garcia CR. Signal transduction in Plasmodiumred blood cells interactions and in cytoadherence. An Acad Bras Cienc. 2012;84:555-72.

16. Kumar P, Tripathi A, Ranjan R, Halbert J, Gilberger T, Doerig C, et al. Regulation of Plasmodium falciparum development by calcium-dependent protein kinase 7 (PfCDPK7). J Biol Chem. 2014;289:20386-95.

17. Bansal A, Singh S, More KR, Hans D, Nangalia K, Yogavel M, et al. Characterization of Plasmodium falciparum calcium-dependent protein kinase 1 (PfCDPK1) and its role in microneme secretion during erythrocyte invasion. J Biol Chem. 2013;288:1590-602.

18. Camilli A, Bassler BL. Bacterial small-molecule signaling pathways. Science. 2006;311:1113-6.

19. Mutai BK, Waitumbi JN. Apoptosis stalks Plasmodium falciparum maintained in continuous culture condition. Malar J. 2010;9(Suppl 3):S6.

20. Pahl HL. Activators and target genes of Rel/NF-kappaB transcription factors. Oncogene. 1999;18:6853-66.

21. Tergaonkar V. NFkappaB pathway: a good signaling paradigm and therapeutic target. Int J Biochem Cell Biol. 2006;38:1647-53.

22. Shen J, Channavajhala P, Seldin DC, Sonenshein GE. Phosphorylation by the protein kinase CK2 promotes calpain-mediated degradation of IkappaBalpha. J Immunol. 2001;167:4919-25.

23. Walliker D, Quakyi IA, Wellems TE, McCutchan TF, Szarfman A, London WT, et al. Genetic analysis of the human malaria parasite Plasmodium falciparum. Science. 1987;236:1661-6.

24. Ockenhouse CF, Betageri R, Springer TA, Staunton DE. Plasmodium falciparum-infected erythrocytes bind ICAM-1 at a site distinct from LFA1, Mac-1, and human rhinovirus. Cell. 1992;68:63-9.

25. Wellems TE, Panton LJ, Gluzman IY, do Rosario VE, Gwadz RW, WalkerJonah A, et al. Chloroquine resistance not linked to mdr-like genes in a Plasmodium falciparum cross. Nature. 1990;345:253-5.

26. Madkhali AM, Alkurbi MO, SzestakT, Bengtsson A, Patil PR, Wu Y, et al. An analysis of the binding characteristics of a panel of recently selected ICAM-1 binding Plasmodium falciparum patient isolates. PLoS One. 2014;9:e111518.

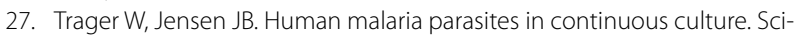
ence. 1976;193:673-5.

28. Dolan SA, Miller LH, Wellems TE. Evidence for a switching mechanism in the invasion of erythrocytes by Plasmodium falciparum. J Clin Invest. 1990;86:618-24

29. Voss TS, Mini T, Jenoe P, Beck HP. Plasmodium falciparum possesses a cell cycle-regulated short type replication protein A large subunit encoded by an unusual transcript. J Biol Chem. 2002;277:17493-501.

30. Yuan X, Russell T, Wood G, Desiderio DM. Analysis of the human lumbar cerebrospinal fluid proteome. Electrophoresis. 2002;23:1185-96.

31. Nirmalan N, Sims PF, Hyde JE. Quantitative proteomics of the human malaria parasite Plasmodium falciparum and its application to studies of development and inhibition. Mol Microbiol. 2004;52:1187-99.

32. Laemmli UK. Cleavage of structural proteins during the assembly of the head of bacteriophage T4. Nature. 1970;227:680-5.

33. Viebig NK, Levin E, Dechavanne S, Rogerson SJ, Gysin J, Smith JD, et al. Disruption of var2csa gene impairs placental malaria associated adhesion phenotype. PLoS One. 2007;2:e910.

34. Hoffmann A, Levchenko A, Scott ML, Baltimore D. The IkappaB-NF-kappaB signaling module: temporal control and selective gene activation. Science. 2002;298:1241-5.

35. Maniatis T. A ubiquitin ligase complex essential for the NF-kappaB, Wnt/Wingless, and Hedgehog signaling pathways. Genes Dev. 1999;13:505-10.

36. Zhang L, Yi Y, Chen J, Sun Y, Guo Q, Zheng Z, Song S. Gambogic acid inhibits Hsp90 and deregulates TNF-alpha/NF-kappaB in HeLa cells. Biochem Biophys Res Commun. 2010;403:282-7.

37. Bravo R, Frank R, Blundell PA, Macdonald-Bravo H. Cyclin/PCNA is the auxiliary protein of DNA polymerase-delta. Nature. 1987;326:515-7.

38. Celis JE, Madsen P, Celis A, Nielsen HV, Gesser B. Cyclin (PCNA, auxiliary protein of DNA polymerase delta) is a central component of the pathway(s) leading to DNA replication and cell division. FEBS Lett. 1987;220:1-7.

39. Moldovan GL, Pfander B, Jentsch S. PCNA, the maestro of the replication fork. Cell. 2007;129:665-79. 
40. Naryzhny SN, Lee $H$. The post-translational modifications of proliferating cell nuclear antigen: acetylation, not phosphorylation, plays an important role in the regulation of its function. J Biol Chem. 2004;279:20194-9.

41. Witko-Sarsat V, Mocek J, Bouayad D, Tamassia N, Ribeil JA, Candalh C, et al. Proliferating cell nuclear antigen acts as a cytoplasmic platform controlling human neutrophil survival. J Exp Med. 2010;207:2631-45.

42. De Chiara A, Pederzoli-Ribeil M, Mocek J, Candalh C, Mayeux P, Millet $A$, et al. Characterization of cytosolic proliferating cell nuclear antigen (PCNA) in neutrophils: antiapoptotic role of the monomer. J Leukoc Biol. 2013;94:723-31.

43. Mitra P, Banu K, Deshmukh AS, Subbarao N, Dhar SK. Functional dissection of proliferating-cell nuclear antigens (1 and 2) in human malarial parasite Plasmodium falciparum: possible involvement in DNA replication and DNA damage response. Biochem J. 2015;470:115-29.

44. Traenckner EB, Pahl HL, Henkel T, Schmidt KN, Wilk S, Baeuerle PA. Phosphorylation of human I kappa B-alpha on serines 32 and 36 controls I kappa B-alpha proteolysis and NF-kappa B activation in response to diverse stimuli. EMBO J. 1995;14:2876-83.

45. Webster MK, Goya L, Firestone GL. Immediate-early transcriptional regulation and rapid mRNA turnover of a putative serine/threonine protein kinase. J Biol Chem. 1993;268:11482-5.

46. Pober JS, Cotran RS. Cytokines and endothelial cell biology. Physiol Rev. 1990;70:427-51.

47. Zwaal RF, Schroit AJ. Pathophysiologic implications of membrane phospholipid asymmetry in blood cells. Blood. 1997;89:1121-32.

48. Gnant MF, Turner EM, Alexander HR Jr. Effects of hyperthermia and tumour necrosis factor on inflammatory cytokine secretion and procoagulant activity in endothelial cells. Cytokine. 2000;12:339-47.

49. Kimura H, Gules I, Meguro T, Zhang JH. Cytotoxicity of cytokines in cerebral microvascular endothelial cell. Brain Res. 2003;990:148-56.

50. Wassmer SC, Cianciolo GJ, Combes V, Grau GE. LMP-420, a new therapeutic approach for cerebral malaria? Med Sci (Paris). 2006;22:343-5 (in French).

51. Chakravorty SJ, Hughes KR, Craig AG. Host response to cytoadherence in Plasmodium falciparum. Biochem Soc Trans. 2008:36:221-8.

52. Hotta CT, Gazarini ML, Beraldo FH, Varotti FP, Lopes C, Markus RP, et al. Calcium-dependent modulation by melatonin of the circadian rhythm in malarial parasites. Nat Cell Biol. 2000;2:466-8.

53. Budu A, Peres R, Bueno VB, Catalani LH, Garcia CR. N1-acetyl-N2-formyl5-methoxykynuramine modulates the cell cycle of malaria parasites. J Pineal Res. 2007;42:261-6.

54. Alves E, Bartlett PJ, Garcia CR, Thomas AP. Melatonin and IP3-induced $\mathrm{Ca} 2+$ release from intracellular stores in the malaria parasite Plasmodium falciparum within infected red blood cells. J Biol Chem. 2011;286:5905-12.

55. Beraldo FH, Mikoshiba K, Garcia CR. Human malarial parasite, Plasmodium falciparum, displays capacitative calcium entry: 2-aminoethyl diphenylborinate blocks the signal transduction pathway of melatonin action on the $P$. falciparum cell cycle. J Pineal Res. 2007;43:360-4.

56. Levano-Garcia J, Dluzewski AR, Markus RP, Garcia CR. Purinergic signalling is involved in the malaria parasite Plasmodium falciparum invasion to red blood cells. Purinergic Signal. 2010;6:365-72.

57. Singh S, More KR, Chitnis CE. Role of calcineurin and actin dynamics in regulated secretion of microneme proteins in Plasmodium falciparum merozoites during erythrocyte invasion. Cell Microbiol. 2014;16:50-63.

58. Citri A, Harari D, Shohat G, Ramakrishnan P, Gan J, Lavi S, et al. Hsp90 recognizes a common surface on client kinases. J Biol Chem. 2006:281:14361-9.

59. Chen Y, Voegeli TS, Liu PP, Noble EG, Currie RW. Heat shock paradox and a new role of heat shock proteins and their receptors as anti-inflammation targets. Inflamm Allergy Drug Targets. 2007;6:91-100.

60. Salminen A, Paimela T, Suuronen T, Kaarniranta K. Innate immunity meets with cellular stress at the IKK complex: regulation of the IKK complex by HSP70 and HSP90. Immunol Lett. 2008;117:9-15.

61. Lewis J, Devin A, Miller A, Lin Y, Rodriguez Y, Neckers L, et al. Disruption of hsp90 function results in degradation of the death domain kinase, receptor-interacting protein (RIP), and blockage of tumor necrosis factor-induced nuclear factor-kappaB activation. J Biol Chem. 2000;275:10519-26.

62. Wang X, Heuvelman DM, Carroll JA, Dufield DR, Masferrer JL. Geldanamycin-induced PCNA degradation in isolated Hsp90 complex from cancer cells. Cancer Invest. 2010;28:635-41.

63. Llinas M, Bozdech Z, Wong ED, Adai AT, DeRisi JL. Comparative whole genome transcriptome analysis of three Plasmodium falciparum strains. Nucleic Acids Res. 2006;34:1166-73.

64. Kastan MB, Bartek J. Cell-cycle checkpoints and cancer. Nature. 2004;432:316-23.

65. Zhu Q, Chang Y, Yang J, Wei Q. Post-translational modifications of proliferating cell nuclear antigen: a key signal integrator for DNA damage response (Review). Oncol Lett. 2014;7:1363-9.

66. Xiong Y, Zhang H, Beach D. D type cyclins associate with multiple protein kinases and the DNA replication and repair factor PCNA. Cell. 1992;71:505-14

67. Gulbis JM, Kelman Z, Hurwitz J, O'Donnell M, Kuriyan J. Structure of the C-terminal region of p21(WAF1/CIP1) complexed with human PCNA. Cell. 1996;87:297-306

68. Knibiehler M, Goubin F, Escalas N, Jonsson ZO, Mazarguil H, Hubscher U, et al. Interaction studies between the p21Cip1/Waf1 cyclin-dependent kinase inhibitor and proliferating cell nuclear antigen (PCNA) by surface plasmon resonance. FEBS Lett. 1996;391:66-70.

69. Maga $G$, Hubscher U. Proliferating cell nuclear antigen (PCNA): a dancer with many partners. J Cell Sci. 2003;116:3051-60.

\section{Submit your next manuscript to BioMed Central and we will help you at every step:}

- We accept pre-submission inquiries

- Our selector tool helps you to find the most relevant journal

- We provide round the clock customer support

- Convenient online submission

- Thorough peer review

- Inclusion in PubMed and all major indexing services

- Maximum visibility for your research

Submit your manuscript at www.biomedcentral.com/submit
() Biomed Central 